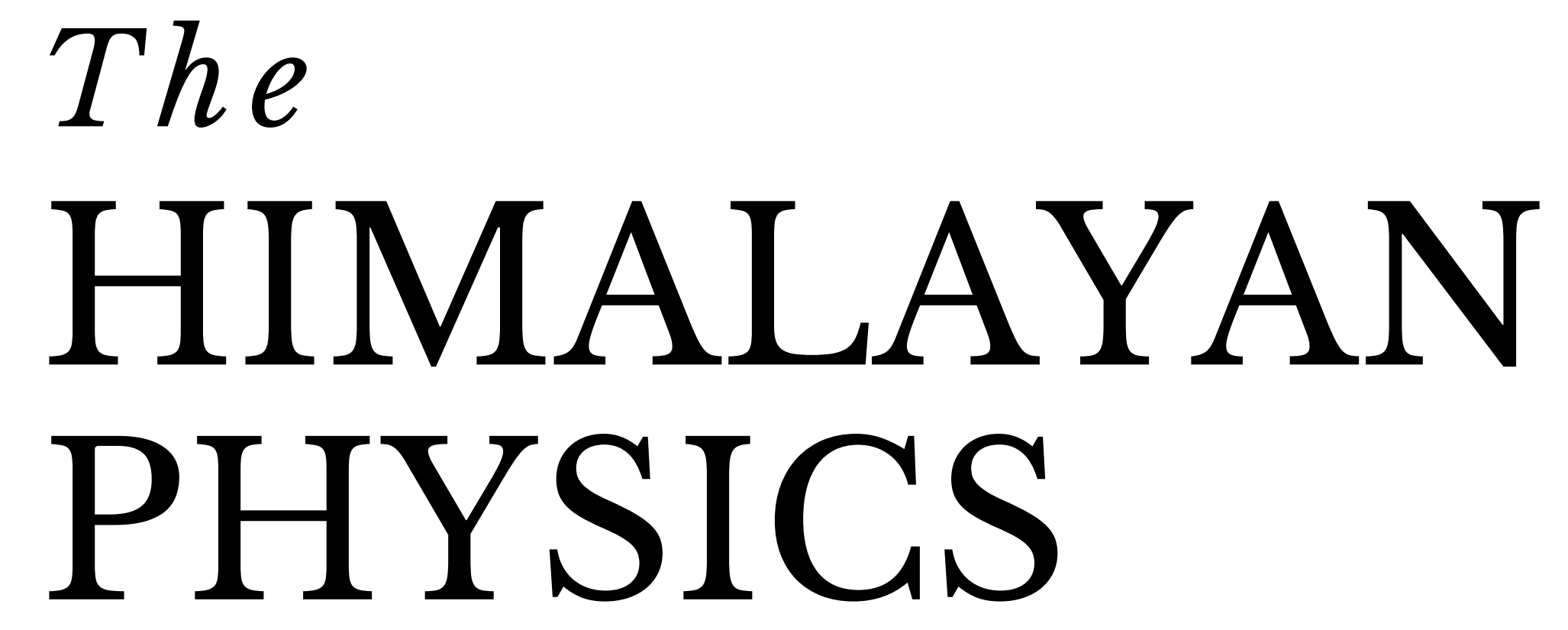

A peer-reviewed Journal of Physics

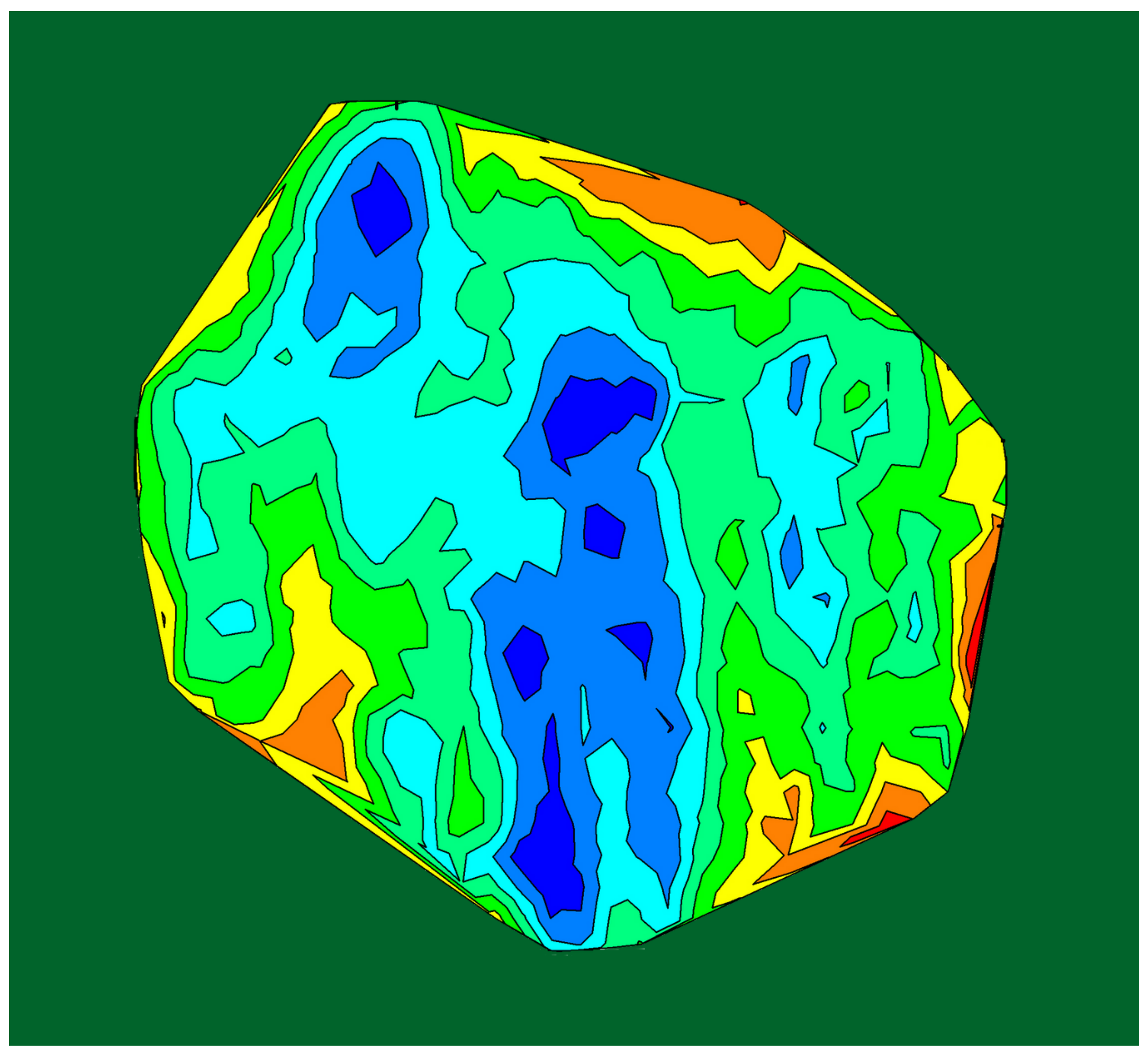

Department of Physics, Prithvi Narayan Campus, Pokhara Nepal Physical Society, Western Chapter, Pokhara 


\section{Publisher}

Department of Physics, Prithvinarayan Campus, Pokhara Nepal Physical Society, Western Chapter, Pokhara

\section{The Himalayan Physics}

Volume 9, December 2020

ISSN 2542-2545

The Himalayan Physics (HimPhys) is an open access peer-reviewed journal that publishes quality articles which make innovative contributions in all areas of Physics. HimPhys is published annually by Nepal Physical Society (Western Regional Chapter), and Department of Physics, Prithvi Narayan Campus, Pokhara. The goal of this journal is to bring together researchers and practitioners from academia in Nepal and abroad to focus on advanced techniques and explore new avenues in all areas of physical sciences and establishing new collaborations with physics community in Nepal.

\section{Chief Editor}

Kapil Adhikari

\section{Associate Editor \\ Aabiskar Bhusal}

(C)2020, Publishers. All rights reserved.

This publication is in copyright. Subject to statutory exception and to the provisions of relevant collective licensing agreements, no reproduction of any part may take place without written permission of the publishers.

Cover: Contour map of dust mass. (C) Mijas Tiwari. Printed from article in the current issue, with permission. 


\section{The HIMALAYAN PHYSICS}

A peer-reviewed Journal of Physics

\section{Chief Editor}

Kapil Adhikari

Associate Editor

Aabiskar Bhusal

\section{Publisher}

Department of Physics, Prithvi Narayan Campus, Pokhara Nepal Physical Society, Western Chapter, Pokhara 


\section{Nepal Physical Society Western Regional Chapter Pokhara, Nepal}

\section{President}

Min Raj Lamsal

Immediate Past President

Jeevan Regmi

Vice-President

Sundar Prasad Dhakal

Secretary

Ravi Karki

Treasurer

Dipak Adhikari

Joint Secretary

Sujan Lamsal

Editorial Member

Kapil Adhikari

Members

Amrit Dhakal

Laxman Thapa

Laxman Timilsina

Narayan Prasad Bhandari

Pradeep Subedi

Advisory Board

Prof. Dr. Pradip K. Bhattarai

Pabitra Mani Poudyal

Surya Bahadur G.C.

Parashu Ram Poudel

Prof. Dr. Shovakanta Lamichhane

Kul Prasad Dahal

Dr. Krishna Raj Adhikari

Ram Sajile Verma 


\section{Himalayan Physics Vol-9 (2020)}

\section{TABLE OF CONTENTS}

Metal Organic Frameworks(MOFs) as efficient carrier for targeted nanodrug delivery

R. Karki, D. Adhikari, K. Adhikari, N. Pantha

A Density Functional Theory Study on Paracetamol-Oxalic Acid Co-Crystal

P. Paudel, K.R. Adhikari, K. Adhikari

First-principles study of $\mathrm{C}$ cites vacancy defects in water adsorbed graphene

H.K. Neupane, N.P. Adhikari

Diusion of fructose in water: a molecular dynamics study

S. Bhusal, N. Pantha

Study of aecting factors of meteorological parameters on solar radiation on Pokhara P.M. Shrestha, J. Regmi, U. Joshi, K.N. Poudyal, N.P. Chapagain, I.B. Karki

Variation of mean value of velocity of ion with dierent obliqueness of magnetized plasma sheath

B.R. Adhikari, H.P. Lamichhane, R. Khanal

Study of dust properties of two far infrared cavities nearby asymptotic giant branch stars under infrared astronomical satellite maps

M. Tiwari, S.P. Gautam, A. Silwal, S. Subedi, A. Paudel, A. K. Jha

An experimental study on irradiated interface of silicon

M.R. Lamsal

Calculation of energy loss of proton beam on thyroid tumor

K. Giri, B. Paudel, B.R. Gautam

Study of noise level status at dierent rice mills in Surkhet Valley, Nepal

D.R. Paudel, H.N. Baral

Elliptically polarized laser assisted elastic electron-hydrogen atom collision and differential scattering cross-section

K. Yadav, S.P. Gupta, J.J. Nakarmi

Geodynamics of Gorkha earthquake (Mw 7.9) and its aftershocks

R.K. Tiwari and H. Paudyal 


\title{
Geodynamics of Gorkha earthquake (Mw 7.9) and its aftershocks
}

Research Article

\author{
Ram Krishna Tiwari ${ }^{1,2 *}$, H. Paudyal ${ }^{2}$ \\ 1 Tribhuvan University, Kirtipur, Kathmandu \\ 2 Birendra Multiple Campus, Tribhuvan University, Bharatpur, Chitwan
}

\begin{abstract}
A devastating earthquake (Mw 7.9) occurred in Gorkha region on 25 April 2015 caused loss of 8964 human lives and huge property in Central Nepal and adjoining region. Sequence of aftershocks, including four having magnitude greater than 6 occurred within 18 days, confined in a distance of about $150 \mathrm{~km}$ from Gorkha to Dolakha. Main shock and its aftershocks series confined in a depth range of 12 to $21 \mathrm{~km}$. In this study, using 11 CMT solutions of earthquakes with magnitude 5 and above, occurred between 2014.12.18 and 2016.11.27 within $84^{\circ}$ to $87^{\circ} \mathrm{E}$ and $27^{\circ}$ to $29^{\circ} \mathrm{N}$, we analyze faulting pattern of the Gorkha earthquake and associated large aftershocks to reveal recent geodynamics pattern in the central Himalayan region.

Nodal planes of mainshock and four large aftershocks have east west orientation and shallow dip $\left(6^{\circ}\right.$ to $\left.23^{\circ}\right)$ towards north, exhibit strong thrust mechanism. Smaller aftershocks scattered within $150 \mathrm{~km}$ long rupture zone along NW to SE direction show similar mechanism with large thrust component. Collective dips of nodal plane of ten events indicate northward under thrusting of the Indian plate at shallow angle, though the nodal plane of individual event differ slightly in their orientation. The cross-sectional study of focal mechanism shows the clustering of the seismic events at different depth with diverse faulting pattern. It is inferred that recent seismic activity in central Nepal region is dominated by thrust faulting and the mechanism which were responsible for the formation of Himalaya are still continuing.
\end{abstract}

Keywords: Seismotectonics • Central Himalaya $\bullet$ Nepal $\bullet$ Clustering

\section{Introduction}

On 25th April 2015 an intense ground shaking struck Central Nepal that caused tremendous damage and loss. The earthquake occurred as a result of the northward under thrusting of India beneath Eurasia. The main shock, approximately $80 \mathrm{~km}$ to the northwest of Kathmandu, occurred in Gorkha at 11:56 (NST) with a magnitude of $\mathrm{Mw} 7.9$ at latitude $27.9^{\circ} \mathrm{N}$ and $85.3^{\circ} \mathrm{E}$ which triggered numerous aftershocks [1]. The biggest of the aftershocks was of the magnitude $\mathrm{Mw} 7.2$ approximately $90 \mathrm{~km}$ southeast from the Mainshock [1]. Multiple studies were carried out by the researchers on the Gorkha Earthquake and its aftershocks sequence to retrieve the rupture process and its tectonic implications [2-4]. A multi-disciplinary effort to understand the earthquake in the context of tectonic evolution of the Himalaya and associated seismic hazards was carried out and the findings suggest

\footnotetext{
* Corresponding Author: ram.tiwari@bimc.tu.edu.np
} 
that segments of the MHT, up-dip of the 2015 Gorkha rupture, likely have high hazard for future damaging earthquakes in this densely populated and vulnerable region [4]. In this study we analyze the faulting pattern of this devastating event and its major aftershocks using CMT moment tensor solutions.

\section{Geo-tectonics of the region}

Central Nepal represents a part of Himalayan geo-tectonic belt. The region is classically divided into four tectonic units from south to north;
1. Sub-Himalaya
2. Lesser Himalaya
3. Higher Himalaya
4. Tethyan Himalaya

Main Frontal Thrust (MFT), Main Boundary Thrust (MBT), Main Central Thrust (MCT) and South Tibet Detachment (STD) separate the four tectonic units (Fig. 1). MFT is the active thrust fault which exposed along the southern edge of the Sub-Himalayan foothills. Both the MFT and MBT sole into the Main Himalaya Thrust (MHT), the detachment along which the Indian plate subducts beneath the Himalaya [5, 6]. MHT dips gently to the north beneath the Lesser Himalaya and further it steepens downward onto a ramp that dives beneath the Higher Himalaya before flattening again northward under the Tethys Himalaya of southern Tibet [7]. It accommodates approximately a half of tectonic convergence between Indian plate and Eurasian plates. Apart from these major thrusts, large number of active faults are identified in the region responsible for frequent generation of earthquake [8] .

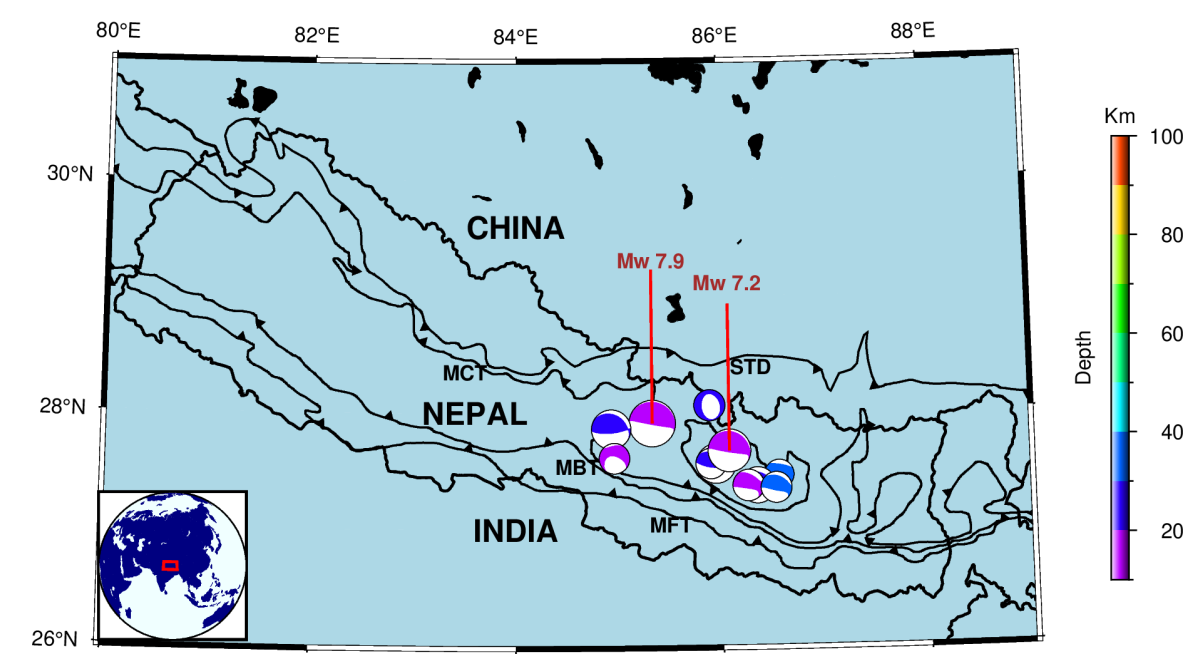

Figure 1. Focal mechanism beachballs solutions of earthquake events (magnitude 5 and above) in the region $\left(26^{\circ} \mathrm{N}-31^{\circ} \mathrm{N}\right.$ and $\left.80^{\circ} \mathrm{E}-89^{\circ} \mathrm{E}\right)$. The red box in the inset map indicates the Nepal in the gobal scenario. The color of the beachball depends on the depth of the event depicted by color bar. 
The term focal mechanism is used to refer to the parameters that characterizes an earthquake rupture. It presents the characteristics of the two orthogonal possible ruptures planes on the basis of strike, dip and rake of the slip vector over the plane. Focal mechanism by Centroid Moment Tensor (CMT) method were constrained by first motion solutions and waveform modelling. The method is based on the linear relationship that exists between the six independent elements of a zeroth order moment tensor representation of an earthquake and the ground motion that the earthquake generates [9]. A moment tensor is a complete description of equivalent forces of a general seismic point source [10] in an elastic medium [11]. The term centroid refers to the center of the earthquake moment distribution in time and space defined by four parameters like centroid latitude, longitude, depth and centroid time. Thus, ten parameters altogether provide the point source CMT representation of an earthquake [1].

Focal mechanism analysis able to describe the source mechanism for the fault planes geometrically and mathematically when the earthquakes occurred. In order to understand the various aspects of earthquake like stress perturbation, aftershocks pattern and faulting geometry etc., an immediate determination of focal mechanism is exceedingly important [12-14]. Focal mechanism data also help in assignment of the tectonic regime by providing information on the relative magnitudes of the principal stresses. In the prediction of ground shaking for early warning purpose, the timely derived focal mechanism can provide significant information such as fault orientation and slipping mode. The faults parameters like strike, dip and slip angles are useful to find out whether the earthquakes have similar source mechanism characteristics or not. The objective of this work is to explain focal mechanism of Gorkha earthquakes of magnitude 5 and above to analyze faulting pattern which could reveal recent geodynamics pattern in the region.

\section{Data and Methodology}

The moment tensor solutions are available for this region in the Harvard CMT Catalogue [3, 4] [Table 1 and Table 2]. We compile the data for the period 2014-1-1 to $2016-12-30$ for latitude range $27^{\circ} \mathrm{N}$ to $29^{\circ} \mathrm{N}$ and longitude range $84^{\circ} \mathrm{E}$ to $87^{\circ} \mathrm{E}$. The original method of constructing beach ball diagrams was the result of analysis of waveforms (the P-wave first motion) generated by an earthquake and recorded by at least 10 seismographs distributed geographically around the epicenter. Here we use the Generic Mapping Tool (GMT) package to construct the map and visualization of beach balls on the map [15]. More precisely, the syntax 'psmeca' is used for representation of the focal mechanism on map of Nepal (Fig. 1) and the syntax 'pscoupe' to plot cross section of focal mechanism (Fig. 2). 
Table 1. : Fault-plane solution parameters of eleven earthquakes from Central Nepal Himalaya and its adjoining regions.

\begin{tabular}{|c|c|c|c|c|c|c|c|c|c|c|}
\hline S.N & Date & Centroid Time (GMT) & Lat. & Lon. & Depth $(\mathrm{km})$ & $\mathrm{Mw}$ & Ms & Strike $\left(^{\circ}\right)$ & $\operatorname{Dip}\left({ }^{\circ}\right)$ & Slip $\left(^{\circ}\right)$ \\
\hline \multirow[t]{2}{*}{1} & 2014-12-18 & $15: 32: 15.4$ & 27.46 & 86.56 & 30.3 & 5.0 & 5.0 & 248 & 26 & 44 \\
\hline & & & & & & & & 117 & 72 & 110 \\
\hline \multirow[t]{2}{*}{2} & $2015-04-25$ & $6: 11: 58.6$ & 27.91 & 85.33 & 12.0 & 7.9 & 7.8 & 287 & 6 & 96 \\
\hline & & & & & & & & 101 & 84 & 89 \\
\hline \multirow[t]{2}{*}{3} & $2015-04-25$ & $6: 45: 53.3$ & 27.86 & 84.93 & 21.0 & 6.7 & 6.6 & 308 & 23 & 131 \\
\hline & & & & & & & & 85 & 73 & 74 \\
\hline \multirow[t]{2}{*}{4} & 2015-04-25 & $17: 42: 53.3$ & 28.06 & 85.89 & 20.8 & 5.3 & 5.1 & 339 & 40 & -105 \\
\hline & & & & & & & & 178 & 52 & -78 \\
\hline \multirow[t]{2}{*}{5} & $2015-04-25$ & 23:16:18.1 & 27.61 & 84.96 & 15.0 & 5.1 & 5.1 & 201 & 40 & -20 \\
\hline & & & & & & & & 306 & 77 & -129 \\
\hline \multirow[t]{2}{*}{6} & 2015-04-26 & $7: 9: 20.1$ & 27.56 & 85.95 & 20.6 & 6.7 & 6.7 & 289 & 14 & 98 \\
\hline & & & & & & & & 101 & 76 & 88 \\
\hline \multirow[t]{2}{*}{7} & 2015-04-26 & $16: 26: 9.6$ & 27.56 & 85.95 & 19.8 & 5.2 & 5.0 & 305 & 26 & 115 \\
\hline & & & & & & & & 98 & 66 & 78 \\
\hline \multirow[t]{2}{*}{8} & 2015-05-12 & $7: 5: 27.5$ & 27.67 & 86.08 & 12.0 & 7.2 & 7.3 & 307 & 11 & 117 \\
\hline & & & & & & & & 99 & 81 & 85 \\
\hline \multirow[t]{2}{*}{9} & 2015-05-12 & $7: 36: 59.6$ & 27.37 & 86.35 & 20.1 & 6.1 & 6.3 & 299 & 28 & 116 \\
\hline & & & & & & & & 90 & 65 & 77 \\
\hline \multirow[t]{2}{*}{10} & 2015-05-16 & $11: 34: 12.6$ & 27.37 & 86.26 & 12.0 & 5.3 & 5.5 & 324 & 34 & 138 \\
\hline & & & & & & & & 91 & 68 & 63 \\
\hline \multirow[t]{2}{*}{11} & 2016-01-12 & 23:35:26.0 & 27.35 & 86.53 & 35.4 & 5.2 & 5.4 & 305 & 24 & 113 \\
\hline & & & & & & & & 100 & 67 & 80 \\
\hline
\end{tabular}

Table 2. : CMT Harvard Centroid Moment Tensor data (psmeca compatible) where mrr, mtt, mpp, mrt, mrp and $\mathrm{mtp}$ are six components of moment Tensor ( $\mathrm{r}$ for $\mathrm{up}, \mathrm{t}$ for south and $\mathrm{p}$ for east) and Iexp is exponent used to convert the scalar moment to units of dyne-cm

\begin{tabular}{ccccccccccc}
\hline S.N & Lon. & Lat. & Depth $(\mathrm{km})$ & mrr & mtt & mpp & mrt & mrp & mtp & Iexp (dyne-cm) \\
\hline 1 & 86.56 & 27.46 & 30 & 1.20 & -3.08 & 1.88 & 2.48 & -0.64 & 1.07 & 23 \\
2 & 85.33 & 27.91 & 12 & 1.76 & -1.82 & 0.06 & 8.04 & -1.51 & 0.48 & 27 \\
3 & 84.93 & 27.86 & 21 & 0.68 & -0.74 & 0.06 & 0.96 & 0.19 & 0.25 & 26 \\
4 & 85.89 & 28.06 & 21 & -1.04 & 0.16 & 0.87 & 0.16 & 0.26 & -0.17 & 24 \\
5 & 84.96 & 27.61 & 15 & -2.08 & -2.46 & 4.54 & 5.53 & -0.90 & -1.20 & 23 \\
6 & 85.95 & 27.56 & 21 & 0.60 & -0.67 & 0.07 & 1.20 & -0.23 & 0.20 & 26 \\
7 & 85.90 & 27.56 & 20 & 5.38 & -5.14 & -0.24 & 5.14 & -0.18 & 2.23 & 23 \\
8 & 86.08 & 27.67 & 12 & 2.70 & -2.62 & -0.08 & 8.25 & -1.28 & 1.22 & 26 \\
9 & 86.35 & 27.37 & 20 & 1.37 & -1.54 & 0.17 & 1.24 & 0.14 & 0.43 & 25 \\
10 & 86.26 & 27.37 & 12 & 0.75 & -0.95 & 0.20 & 0.83 & 0.04 & 0.63 & 24 \\
11 & 86.53 & 27.35 & 35 & 0.56 & -0.61 & 0.05 & 0.62 & -0.08 & 0.29 & 24 \\
\hline
\end{tabular}




\section{Results and Discussion}

The mainshock $(7.9 \mathrm{Mw})$ shows $\mathrm{N} 17^{\circ} \mathrm{E}$ dipping with strike direction $\mathrm{N} 73^{\circ} \mathrm{W}$ while the aftershocks $(\mathrm{Mw} 6.6)$ occurred in the same day shows $\mathrm{N} 38^{\circ} \mathrm{E}$ dipping with strike direction $\mathrm{N} 52^{\circ} \mathrm{W}$. The aftershock (Mw 6.7$)$ on the day after the mainshock shows the dipping with direction $\mathrm{N} 19^{\circ} \mathrm{E}$ and $\mathrm{N} 71^{\circ} \mathrm{W}$ and the major aftershocks on 12 May 2015 has again shows dipping with dip direction $\mathrm{N} 37^{\circ} \mathrm{E}$ and striking with direction $\mathrm{N} 53^{\circ} \mathrm{W}$. This indicates that the strike direction is confined on NW and the propagation of the rupture is mainly concentrated along NE direction. The angle of dip of mainshock was $6^{\circ}$ and its largest aftershock was $11^{\circ}$. Nodal planes of mainshock and three large aftershocks have east west orientation and shallow dip $\left(6^{\circ}\right.$ to $\left.23^{\circ}\right)$ towards north, exhibit strong thrust mechanism. The dips of nodal plane of other larger aftershocks ( $\mathrm{Mw} 5.1$ to 6.7 ) lying between $14^{\circ}$ to $40^{\circ}$ indicate dipping process at shallow angle in the region, steeper than the detachment MHT which is demarcated as a low-angle northeast dipping at depth of 12-21 km [9].

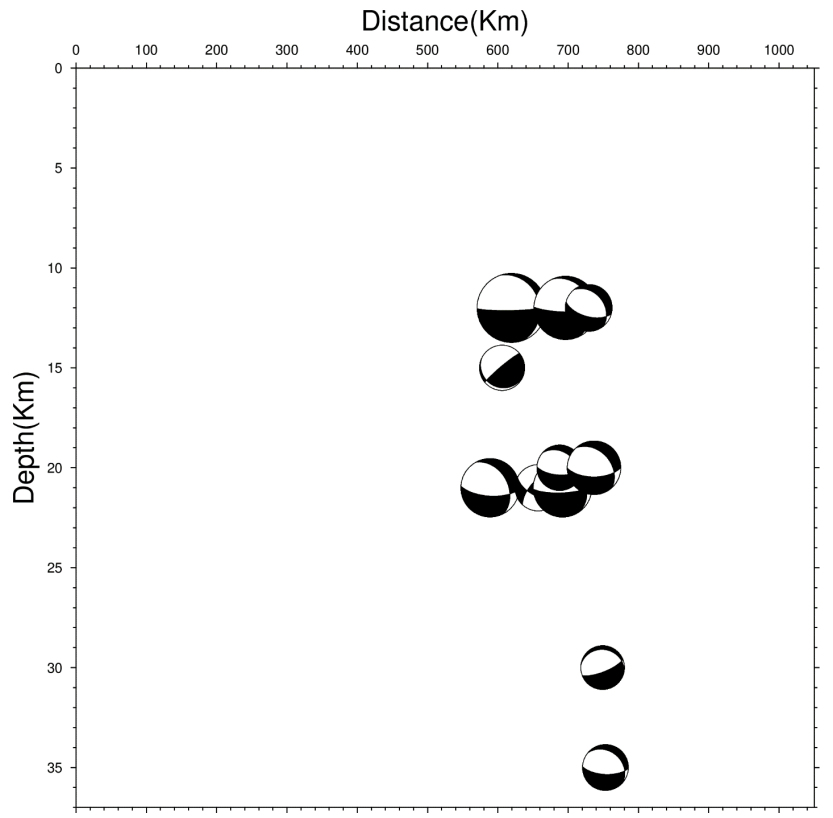

Figure 2. Focal mechanism cross-section of 11 events having magnitude 5 and above $\left(26^{\circ} \mathrm{N}-31^{\circ} \mathrm{N}\right.$ and $\left.80^{\circ} \mathrm{E}-89^{\circ} \mathrm{E}\right)$ with depth.

The cross-section map (Fig. 3) associated with mainshock and aftershocks shows the depth range from 10 $\mathrm{km}$ to $35 \mathrm{~km}$. The mainshock (Mw7.9) and major aftershock (Mw7.2) both occurred at depth of $12 \mathrm{~km}$. The focal mechanism cross section map (Fig. 2) shows two remarkable clustering. There is one cluster around depth $12 \mathrm{~km}$ and another cluster around $20 \mathrm{~km}$ to $21 \mathrm{~km}$. The seismic event gap was noticed between these two clusters. The group of researchers [16] noticed the thrusting on a sub horizontal fault dipping about $10^{\circ}$ northwards and the 15 km hypo central depth. They made the conclusion that this earthquake ruptured the MHT, the main fault along which northern India underthrusts the Himalaya at a rate of approximately $2 \mathrm{cmyr}^{-1}$. Zhang et al. [2] reported the focal mechanism of this earthquake is a thrust fault type and is consistent with the Main Frontal Thrust. 
Thus, focal mechanism of Gorkha earthquake explained in this study is agreement with the earlier works.

\section{Conclusion}

The focal mechanism of the 2015 Nepal earthquake was the thrust fault type, which is consistent with the Main Frontal Thrust. The rupture propagated from the hypocenter toward southeast and did not cause surface rupture. Clustering patterns of events is observed following NW-SE trend of the major thrust. Most of the aftershocks are occurred to the SE of main shock than that in NW of it and within 10 to $35 \mathrm{~km}$ depth range. The strong thrust mechanism was exhibited by the events as noticed from orientation of nodal planes of mainshock and four large aftershocks. They have east west orientation and shallow dip $\left(6^{\circ}\right.$ to $\left.23^{\circ}\right)$ towards north. The strain resulting from on-going collision between India and Eurasian plates could have cause large slip on the locked segment of the detachment (MHT) to generate the Mw7.9 devastating Gorkha earthquake. Focal mechanism cross sections highlight a region of the MHT that has not ruptured in this event, but is locked, and therefore still has the potential to fail seismically.

\section{Acknowledgements}

One of the authors RKT would like to acknowledge Tribhuvan University, Nepal for providing sabbatical leave and University Grants Commission (UGC), Nepal for providing financial support in the form of fellowship.

\section{References}

[1] Ekstrom G, Nettles M, Dziewo'nski A. The global CMT project 2004-2010 Centroid-moment tensors for 13,017 earthquakes. Physics of the Earth and Planetary Interiors. 2012;200:1-9.

[2] Zhang L, Li J, Liao W, Wang Q. Source rupture process of the 2015 Gorkha, Nepal Mw7. 9 earthquake and its tectonic implications. Geodesy and geodynamics. 2016;7(2):124-131.

[3] Fan W, Shearer PM. Detailed rupture imaging of the 25 April 2015 Nepal earthquake using teleseismic P waves. Geophysical Research Letters. 2015;42(14):5744-5752.

[4] Arora B, Bansal B, Prajapati SK, Sutar AK, Nayak S. Seismotectonics and seismogenesis of Mw7. 8 Gorkha earthquake and its aftershocks. Journal of Asian Earth Sciences. 2017;133:2-11.

[5] Paudyal H, Shanker D, Singh H, Panthi A, Kumar A, Singh V. Current understanding of the seismotectonics of Western Nepal Himalaya and vicinity. Acta Geodaetica et Geophysica Hungarica. 2010;45(2):195-209.

[6] Thapa DR, Tao X, Fan F, Tao Z. Aftershock analysis of the 2015 Gorkha-Dolakha (Central Nepal) earthquake doublet. Heliyon. 2018;4(7):e00678.

[7] Elliott J, Jolivet R, González PJ, Avouac JP, Hollingsworth J, Searle M, et al. Himalayan megathrust 
geometry and relation to topography revealed by the Gorkha earthquake. Nature Geoscience. 2016;9(2):174180.

[8] Dasgupta S, Mukhopadhyay M, Nandy D. Active transverse features in the central portion of the Himalaya. Tectonophysics. 1987;136(3-4):255-264.

[9] Gilbert F. Excitation of the normal modes of the Earth by earthquake sources. Geophysical Journal International. 1971;22(2):223-226.

[10] Jost Mu, Herrmann R. A students guide to and review of moment tensors. Seismological Research Letters. 1989;60(2):37-57.

[11] Shearer P, Hauksson E, Lin G. Southern California hypocenter relocation with waveform cross-correlation, Part 2: Results using source-specific station terms and cluster analysis. Bulletin of the Seismological Society of America. 2005;95(3):904-915.

[12] Michael AJ. Use of focal mechanisms to determine stress: a control study. Journal of Geophysical Research: Solid Earth. 1987;92(B1):357-368.

[13] King GC, Stein RS, Lin J. Static stress changes and the triggering of earthquakes. Bulletin of the Seismological Society of America. 1994;84(3):935-953.

[14] Moore G, Bangs N, Taira A, Kuramoto S, Pangborn E, Tobin H. Three-dimensional splay fault geometry and implications for tsunami generation. Science. 2007;318(5853):1128-1131.

[15] Wessel P, Luis J, Uieda L, Scharroo R, Wobbe F, Smith W, et al. The generic mapping tools version 6. Geochemistry, Geophysics, Geosystems. 2019;20(11):5556-5564.

[16] Avouac JP, Meng L, Wei S, Wang T, Ampuero JP. Lower edge of locked Main Himalayan Thrust unzipped by the 2015 Gorkha earthquake. Nature Geoscience. 2015;8(9):708-711. 